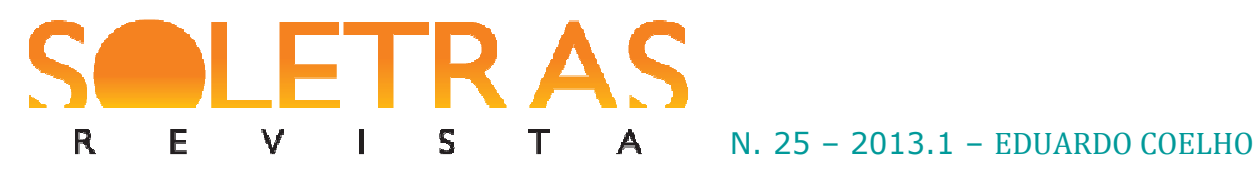

\title{
Manuel Bandeira camufla Blaise Cendrars
}

Eduardo Coelho ${ }^{1}$

Resumo: Análise da recepção crítica de Blaise Cendrars no Brasil. Exame mais minucioso da recepção da obra de Blaise Cendrars por Manuel Bandeira, quando são examinadas cartas, crônicas e poemas do escritor recifense. Considerações a respeito da poética cendrarsiana, com ênfase nas suas transformações mais notáveis dos anos 1910 aos anos 1920. Levantamento de características da poética cendrarsiana notáveis na obra de Oswald de Andrade e de Manuel Bandeira. Observação da tentativa de "rasura" da presença de Blaise Cendrars na poética bandeiriana.

Palavras-chave: Poesia. Modernismo. Manuel Bandeira. Blaise Cendrars.

O poeta e prosador franco-suíço Blaise Cendrars foi, sem qualquer dúvida, uma das influências mais notáveis entre os modernistas brasileiros. No ano de 1924 - quando veio ao Brasil a convite de Paulo Prado -, Mário de Andrade, Menotti Del Picchia, Oswald de Andrade, Paulo Prado e Sérgio Buarque de Holanda escreveram artigos laudatórios em relação à obra cendrarsiana.

Oswald de Andrade, a 13 de fevereiro, afirma, no Correio Paulistano, que Blaise Cendrars é "apenas a singular reaparição do gênio da livre poesia na França”, com uma "percepção acima do comum" e grande "sensibilidade contemporânea". Destaca a capacidade sem igual de ele observar "o mundo" das cidades e viagens, quando revela, por meio de sua poesia, "a forte e desembaraçada beleza da vida". Analisa diversas características de sua obra, como o recorte de "quadros modernos", a agudeza da prosa telegráfica, cinematográfica e precisa, em que o verbalismo anacrônico foi abandonado (ANDRADE, apud EULÁLIO, 2001, p. 381-382).

A Revista do Brasil, de março daquele ano de 1924, publicou um artigo de Mário de Andrade que enaltece, com o mesmo fervor de Oswald, a obra cendrarsiana. Por meio de uma crítica refinada, Mário de Andrade observa que na prosa de Blaise Cendrars cada palavra e frase curta, "de significação exata, essencial", concorre por "justaposição, em síntese sistemática, para uma arquitetura extraordinariamente equilibrada e franca”. Revela a força

\footnotetext{
${ }^{1}$ Eduardo Coelho foi chefe do Arquivo-Museu de Literatura Brasileira da Fundação Casa de Rui Barbosa. Publicou, em 2003, a antologia Manuel Bandeira na coleção Melhores Crônicas, da editora Global. É professor de Literatura Brasileira da Faculdade de Letras da Universidade Federal do Rio de Janeiro, coordenador do Arquivo Augusto Boal e colunista da revista portuguesa Ler.
} 
cinemática de suas obras, que cria uma "vida intensa" e "dramática", capaz também de ser primitiva ao reunir inovações dos tempos modernos às frases musicais e às lendas dos negros. Examina, quase sempre de modo positivo, recursos da prosa e da poesia de Cendrars, como a sua habilidade de compor versos curtos, isentos de retórica; a naturalidade de seus textos; o processo de associações de imagens, em que o poeta se liberta das funções cognitivas da inteligência - "a razão, a consciência, a compreensão intelectiva (milhor: a apreensão), e principalmente a imaginação que desvirtuam a realidade". Ainda segundo Mário de Andrade, nas “obras-primas" Prose du Transsibérien e Le Panama encontra-se a mais "pura e perfeita manifestação [...] da verdadeira liberdade", em que, "à correspondência exata entre a expressão formal e o lirismo puro, se liga [...] o equilíbrio entre a manifestação subconsciente e a consciência" (Apud EULALIO, 2001, p. 384-394). Embora faça pequenas restrições a algumas técnicas de Blaise Cendrars, elas não comprometem de modo algum seu maravilhamento pela obra desse escritor.

Assim seguia o trem modernista, com diversos autores que compartilhavam da mesma estima pelas obras de Blaise Cendrars, tornando-o, consequentemente, a principal influência do grupo a partir de 1924. Contudo, nos dois volumes da edição Poesia e prosa, de Manuel Bandeira, existe apenas uma referência ao seu nome, no poema "Rondó do Palace Hotel", de Estrela da Manhã: "Toca [Cícero Dias] um jazz de pandeiros com a mão / Que o Blaise Cendrars perdeu na guerra." (BANDEIRA, 1958, p. 263). Os demais registros acerca desse autor estão no livro póstumo Crônicas inéditas I - em "Mário de Andrade", de outubro de

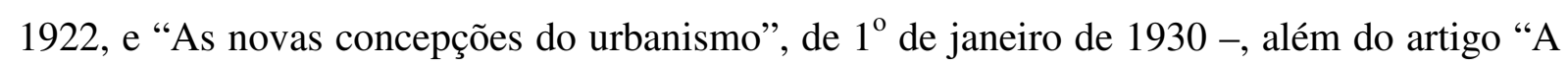
poesia de Blaise Cendrars e os poetas brasileiros", escrito tardiamente em relação ao modernismo, a 14 de julho de 1957, para o Journal Français du Brésil, bem como a crônica "Cendrars daquele tempo", de 25 de janeiro de 1961, reproduzida em Andorinha, andorinha.

Eis os trechos de Crônicas inéditas I:

A Pauliceia desvairada é um livro impressionista. O desvairismo é escrever sem pensar tudo o que o inconsciente grita quando explode o acesso lírico. Os românticos escreviam assim. Foi assim também que Rimbaud escreveu as Iluminações. Rimbaud - avô de Blaise Cendrars! ["Mário de Andrade"] (BANDEIRA, 2008, p. 25).

E ainda:

[...] o próprio valor de Le Corbusier como artista renovador justifica 
plenamente a nossa insistência [a crônica anterior também falava de Le Corbusier]. Le Corbusier é suíço de nascimento. Suíço é o poeta Blaise Cendrars. ["As novas concepções do urbanismo"] (BANDEIRA, 2008, p. 282).

Já no artigo "A poesia de Blaise Cendrars e os poetas brasileiros", publicado fora do contexto modernista, Manuel Bandeira "confessa":

[...] Ribeiro Couto e eu sabíamos de cor diversas passagens desses poemas [Prose du Transsibérien e Les Pâques à New York], e creio talvez poder confessar ter sido Cendrars quem levantou em mim o gosto da poesia do cotidiano. E foi sem dúvida de Cendrars também que veio em grande parte o gosto dos poetas modernistas pela poesia do prosaico cotidiano. E quem sabe se ainda o gosto pelo poema-piada? (EULÁLIO, 2001, p. 460).

Mais do que a confissão da influência de Blaise Cendrars, surpreende a expressão “creio talvez poder confessar". Trata-se de um sintagma-chave para compreender a relação de Manuel Bandeira com o poeta franco-suíço. Publicado em 1957, três décadas após a euforia modernista em torno da obra cendrarsiana, Manuel Bandeira ainda revela uma dúvida latente acerca da pertinência ou não de confessar a importância do autor de Le Panama para a formação de sua poética cotidiana e simples. O sintagma-chave mostra que há pudor em tal declaração, chamando a atenção para o seu interesse de manter-se desvinculado do grupo modernista, mesmo tanto tempo depois do surgimento do temor, nos anos 1920.

Depois, em "Cendrars daquele tempo", revela novamente o interesse que sentia pelas obras cendrarsianas:

[...] A sua poesia impressionava então violentamente pela mistura do épico e do lírico: ao mesmo tempo que representava a vida moderna no que ela tinha de mais novo e mais chocante, sabia confidenciar os sentimentos mais íntimos do seu autor. Cendrars era possuído da vida moderna. [...]

No Brasil foi grande a sua influência sobre os rapazes que em 22 desencadearam o movimento modernista. Tanto que, alguns anos depois da famosa Semana, indo Paulo Prado à Europa, trouxe de Paris o poeta para lhe mostrar o Rio, São Paulo e Minas. Algumas das impressões dessa passagem entre nós estão nos poemas curtos do livro Feuilles de Route, poeminhas que evidentemente influenciaram a maneira em que depois começou a poetar o "aluno de poesia" Oswald de Andrade.

[...]

Quem me revelou Blaise Cendrars foi Ribeiro Couto, quando éramos vizinhos na Rua do Curvelo. Ainda hoje conservo preciosamente o exemplar de Du Monde Entier [que reúne os livros Les Pâques à New York, La Prose du Transsibérien e Le Panama] na simpática edição da Nouvelle Revue Française, emprestado por Couto e que eu jamais restituí. Lembro- 
me nitidamente do fervor com que líamos e relíamos os versos, tão surpreendentes para nós, de "Les Pâques à New York", "Prose du Transsibérien" e "Le Panama"... Versos que hoje não me satisfazem mais, mas que naquele tempo punham em meu coração um frêmito novo... (BANDEIRA, 1966, p. 340).

Diante desse trecho, é no mínimo curioso que Blaise Cendrars tenha aparecido, nos textos bandeirianos da fase mais modernista, apenas como "apêndice" de Cícero Dias, Le Corbusier, Mário de Andrade e Arthur Rimbaud. São referências pouco representativas tendo em vista a admiração expressa da geração da Semana de Arte Moderna, que dedicou uma série de artigos à poesia e à prosa cendrarsianas. O caso torna-se ainda mais instigante quando se toma conhecimento das referências que Manuel Bandeira fez a ele em cartas dos anos 1920:

[...] Tu recebestes o J'ai tué de Blaise Cendrars, que te enviei? O poeta é exatamente aquele que tem o senso das realidades. [A Ribeiro Couto, em 1923. $]^{2}$

Está fazendo um calor safado. "Je suis dans ma chambre enfermé comme dans du beurre fondu" como diz Cendrars na deliciosa primeira plaquete ["Dimanche"] das Feuilles de route, cujos primeiros exemplares apareceram ontem nas livrarias daqui. [A Mário de Andrade, a 31 de janeiro de 1925]. (ANDRADE; BANDEIRA, 2000, p. 186).

A respeito do seu artigo sobre o livro de Cendrars [sobre Feuilles de Route; o artigo foi publicado na revista Estética de janeiro-março de 1925]: acho impertinente o seu ataque. Você tem razão na distinção que faz entre poesia e lirismo. Mas tudo está indicando (título, assunto, técnica) que o livro é reportagem lírica; impressões, instantâneos como os daquele outro livro que ele chamou com tanta propriedade Kodak. A menos que você entenda negar ao poeta o direito de fazer lirismo puro. Você pode no artigo aproveitar a ocasião, muito oportuna, de apresentar a distinção entre lirismo e poesia, chamando para ela a atenção dos poetas, mas sem envolver censura ao livro cujo caráter é lírico - reportagem lírica. E deliciosa, hein? "Vivre dans la compagnie d'un gros bananier", que coisa estupenda! Achei de uma frescura de impressões! O seu Losango cáqui tem isso também. Não é a maior delícia do lirismo? [A Mário, a 16 de abril de 1925] (ANDRADE; BANDEIRA, 2000, p. 198).

A expressão "frescura de impressões" diz respeito ao registro mental típico da "reportagem lírica", em que as cenas se revelam com naturalidade e simplicidade. Trata-se aqui da mesma sensação de frescura dos poemas "Pensão familiar", "Mangue" e "Evocação

\footnotetext{
${ }^{2}$ Todos os trechos citados de cartas de Bandeira para Ribeiro Couto foram extraídas do ARQUIVO RIBEIRO COUTO, Arquivo-Museu de Literatura Brasileira - AMLB, Fundação Casa de Rui Barbosa.
} 
de Recife", que Manuel Bandeira incorporou muito bem a sua própria lírica.

A 19 de setembro de 1925, mostrou uma compreensão madura tanto da poética de Oswald de Andrade quanto da de Blaise Cendrars: "Oswald mandou-me o Pau-Brasil. Que capa f. da p.! Aquilo sim, é arte brasileira 'saída dos discursos da câmara, dos comentários dos jornais, etc.' O que está dentro é o bom Oswald, empregando a técnica de Kodak de Cendrars" (ANDRADE; BANDEIRA, 2000, p. 328). Fica claro que ele gosta justamente do que, no livro de Oswald de Andrade, provém da poética cendrarsiana.

Por fim, outras declarações de apreço ao escritor franco-suíço:

[...] A técnica de ambos [Oswald de Andrade e Sérgio Milliet] foi tirada do Cendrars [...]. [Para Mário, a 19 de setembro de 1925];

[...] Batuta é o Cendrars na Metaphysique. [Para Ribeiro Couto, em 1926];

Passei o dia de ontem lendo a edição [do Jornal, outubro de 1927];

Achei excelente a coisa do Cendrars. [Para Couto, a 17 de outubro de 1927];

[...] o poeta, o poeta verdadeiro é o homem que possui o senso das realidades (Blaise Cendrars, J'ai tué) [...]. [Para Couto, a 19 de outubro de 1927]. ${ }^{3}$

Por meio destes fragmentos, observa-se que Manuel Bandeira tinha absoluta consciência do quanto, nos anos 1920, a obra cendrarsiana influenciou os poetas modernistas. Mário de Andrade, Oswald de Andrade e Sérgio Milliet são mencionados a respeito disso, além de ele próprio demonstrar, com afirmações entusiasmadas, interesse pelo "senso das realidades" e pelas "reportagens líricas" dos versos de Blaise Cendrars, o que mais parece, nas cartas, uma descrição da poesia bandeiriana. A frase "Nós derivamos todos de ApollinaireCendrars", da carta de 11 de agosto de 1925, ainda serve como prova material dessa tese de influência. ${ }^{4}$

No entanto, a partir de uma leitura superficial, tal admiração quase não se reflete em Libertinagem, sua obra que corresponde à fase mais vibrante da recepção crítica acerca das técnicas criativas de Blaise Cendrars, criando uma dissonância entre o que declara nas cartas e o que faz no campo da criação poética. Exceto no "Poema tirado de uma notícia de jornal",

\footnotetext{
${ }^{3}$ Todas as citações foram colhidas de Andrade; Bandeira, 2000, p. 241-242.

${ }^{4}$ Cf. ARQUIVO RIBEIRO COUTO, Arquivo-Museu de Literatura Brasileira - AMLB, Fundação Casa de Rui Barbosa.
} 
$\begin{array}{lllllllll}\mathbf{R} & \mathbf{E} & \mathbf{V} & \mathbf{I} & \mathbf{S} & \mathbf{T} & \mathbf{A} & \text { N. } 25-2013.1 \text { - EDUARDO COELHO }\end{array}$

parece difícil encontrar a presença da obra do escritor franco-suíço na poesia de Manuel Bandeira. Embora haja menos referências à poética de Guillaume Apollinaire nos seus textos, observamos que, em se tratando do pensamento apollinaireano. A proposta de uma relação mais produtiva da arte moderna com a tradição é um ponto central da reflexão crítica de Guillaume Apollinaire, bem como da poética bandeiriana, ao contrário do que se passa em relação a Blaise Cendrars. Não se pretende afirmar aqui, porém, que haja uma relação direta da poesia de Manuel Bandeira com a de Apollinaire. Tecnicamente, suas obras são muito diferentes. No entanto, há uma busca de recuperação de elementos da tradição que revelaram, quando criados, algum caráter modernizante. O Bestiário, de Guillaume Apollinaire, e certas questões tratadas na revista L'Esprit Nouveau são exemplares nesse sentido.

Em A poesia de Manuel Bandeira: humildade, paixão e morte, Davi Arrigucci Jr. sinaliza, a partir da crônica "Cendras daquela época", que Manuel Bandeira fez uma leitura a respeito da obra do poeta franco-suíço. Para Davi Arrigucci, essa crônica apanha

[...] aspectos fundamentais, pois caracterizam o núcleo da poética que tanta importância teve para a definição dos rumos da poesia moderna na década de 1920: a matéria nova e chocante, cujo caráter jornalístico e prosaico marcava o deslocamento da noção de poético (1990, p. 100).

Segundo o crítico, eram "[m]atéria e forma novas" de Blaise Cendrars que, "naqueles anos, $[\ldots]$ poderiam muito bem caracterizar o achado do próprio Bandeira no 'Poema tirado de uma notícia de jornal'” (ARRIGUCCI JR, 1990, p. 100). A análise é correta, formulando brevemente a relação de influência de Blaise Cendrars na poética bandeiriana; no entanto, o aproveitamento da notícia para elaboração de poemas bandeirianos é um caso isolado no contexto de sua obra reunida.

Torna-se necessário lembrar que a obra cendrarsiana revela, se observada diacronicamente, uma série de técnicas criativas relacionadas com os princípios das vanguardas. Não houve propriamente qualquer adesão sua a uma escola específica futurismo, dadaísmos ou surrealismo —, mas ele absorveu, em cada livro, aspectos referentes a tais vanguardas à medida que os conteúdos programáticos dos vários grupos eram revelados através de manifestos e revistas. Se não se pode enquadrar a poesia de Blaise Cendrars em qualquer um desses movimentos, é possível, no entanto, relacioná-la a todos eles. De $L a$ Prose du Transsibérien a Feuilles de Route, a poética cendrarsiana mostra características diversas, ainda que sempre em busca de processos criativos inovadores. Desse modo, seria 


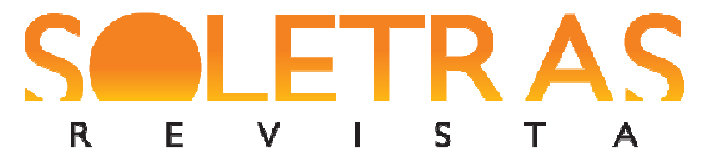

necessário que se fizesse uma avaliação dos elementos que representam a influência de Blaise Cendrars nas obras dos autores modernistas e, em nosso caso, verificar se Manuel Bandeira não se apropriou, com mais frequência, de elementos abandonados pela geração de 1922. Diante de tantas afirmações entusiasmadas em sua correspondência, suspeita-se que tal influência possa se revelar de outra maneira, ou seja, mediante a incorporação de elementos cendrarsianos menos apreciados pelo grupo modernista ou por meio de acréscimos pessoais que modificariam os componentes "tirados", por Manuel Bandeira, da obra de Blaise Cendrars, dificultando, consequentemente, o reconhecimento da influência. O poeta recifense não queria, de modo algum, ser associado a qualquer grupo e defendia a absoluta liberdade de criação, o que o título de seu livro mais modernista também indicia: Libertinagem.

A maior parte dos modernistas apropriou-se das técnicas de Blaise Cendrars elaboradas em Dix-neuf Poémes Élastiques, de 1919; Anthologie Nègre, de 1922; e sobretudo as que foram trabalhadas nos livros Kodak e Feuilles de Route I, Le Formose, ambos de 1924. Entre os livros de 1919 e 1924, observamos algumas características recorrentes, que posteriormente serão absorvidas pelos autores do modernismo brasileiro: a descrição cinematográfica; a livre associação de imagens; a libertação dos "entraves" do processo cognitivo na criação, em que se dava margem às interferências do subconsciente; presença constante da mescla de gêneros - o lírico e o épico, conforme Manuel Bandeira na crônica "Cendrars daquele tempo"; simplificação da matéria poética, extremamente coloquial e prosaica, além da ironia e do poema-piada. Estas caraterísticas, porém, também são comuns em diversas vanguardas, como o futurismo e o surrealismo, bem como em relação ao esprit noveau de Guillaume Apollinaire. O que parece fundamental observar, nesse caso, é que todos os modernistas aproveitaram, à maneira cendrarsiana, a técnica da descrição cinematográfica, crua e simples, que abandona a imaginação e o discurso retórico. O mesmo se passa com a técnica kodak, com que Blaise Cendrars registrava cenas do cotidiano, com uma linguagem concisa, econômica, não mais ligada estritamente ao imaginário e à escrita lógico-racional, tão frequentes nos processos criativos mais tradicionais do século XIX.

Em Libertinagem, existem apenas, entre tais elementos, três aspectos nada frequentes: a piada, a técnica de escrita cinematográfica e a técnica kodak, compostas com versos e poemas curtos. Trata-se justamente dos elementos mais próximos de Oswald de Andrade, o principal representante dessa tendência na literatura modernista, de quem Manuel Bandeira pretendia se afastar para evitar a "contaminação" pau-brasil que atacava muitos jovens poetas. Diante disso, não fui um afastamento por desinteresse em torno da obra oswaldiana, mas por 


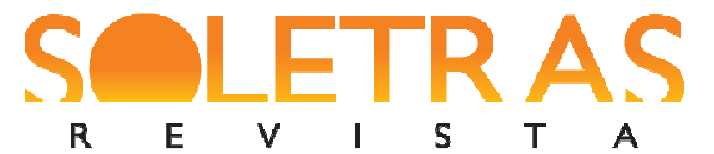

considerar que adesão em larga escala aos pressupostos do "Manifesto da poesia pau-brasil" estava enfraquecendo a originalidade do antilirismo do companheiro de geração.

O interesse de Manuel Bandeira em torno da obra de Blaise Cendrars fica concentrado na simplicidade da matéria poética, que sem dúvida também pode ser encontrada nos poemaspiada e na escrita cinematográfica desenvolvido por outros autores. Contudo, a descoberta da poesia do cotidiano não foi reproduzida da mesma forma por Manuel Bandeira: ele preferiu, no lugar da técnica cinematográfica (muito fragmentada) e da técnica kodak, a linguagem prosaica, com uma sintaxe mais tradicional, mesmo quando absorvia elementos da língua falada. Dessa maneira, Manuel Bandeira desviou-se da possível identificação da sua obra com a de Blaise Cendrars, o que se deve a uma "angústia da influência" relacionada com a ideia da formação de grupos. Em razão disso, mesmo tendo imenso apego à aparente espontaneidade e à simplicidade dos poemas cendrarsianos, que desenvolvia cenas realistas do cotidiano, incorporando, com frequência, notícias de jornal e trechos de conversas - o "senso das realidades" e as "reportagens líricas" -, foi apenas em 1957 que Manuel Bandeira considerou que podia confessar ter sido Blaise Cendrars quem levantou nele o gosto da poesia do cotidiano (EULÁLIO, 2001, p. 460).

Em se tratando das características que não foram muito aproveitadas pelo grupo de 1922, destaquemos o relevante título de um dos seus livros, Le Panama ou Les Aventures des Mes Sept Oncles, de 1918. É inevitável não se pensar, logo de imediato, nas personagens da vida de Manuel Bandeira incorporadas a seus poemas, como Aninha Viegas, Totônio Rodrigues, seu avô (todos aparecem em "Evocação do Recife") e Rosa ("Vou-me embora pra Pasárgada"). Segundo Manuel Bandeira, dos seis aos dez anos de idade ele construiu a sua mitologia, em que alguns tipos - "um Totônio Rodrigues, uma D. Aninha Viegas, a preta Tomásia", velha cozinheira da casa de seu avô — revelavam, para ele, "a mesma consistência heroica das personagens dos poemas homéricos" (BANDEIRA, 1954, p. 12), assim como em Blaise Cendrars, que ouviu da própria mãe a história dos sete irmãos dela, a qual transporia para as aventuras do livro Le Panama, sem que haja a possibilidade calcular o quanto desse poema é biográfico e histórico, bem como o quanto é pura criação ou a mistura das duas coisas.

Nesse sentido, vale a pena destacar o início de Le Panama ou Les Aventures des Mes Sept Oncles, pois as semelhanças com a primeira estrofe de "Evocação do Recife" são muito representativas. Ambos desprezam a história oficial e buscam, por meio da construção poética, compor versos a partir de um olhar subjetivo e pessoal: 
Des livres

Il y a des livres qui parlent du Canal de Panama

Je ne sais pas ce que les journaux financiers

Quoique les bulletins de la Bourse soient notre prière quotidienne

Le Canal de Panama est intimement lié à mon enfance... (CENDRARS, 2005, p. 102). ${ }^{5}$

A construção do canal do Panamá foi um dos maiores fracassos da III Re- pública francesa, com escândalos políticos, falências e suicídios. Muitos franceses envolvidos no projeto ficaram arruinados, como o pai de Blaise Cendrars, homem de negócios que levava a família de cidade em cidade à procura de sucesso financeiro (CENDRARS, 2005, p. 105107). Devido a tal malogro, deixaram o Panamá. Nessa mesma época, ainda criança, Cendrars leu a respeito do terremoto de Lisboa de 1755, que muito o impressionou. Posteriormente, concluiu, segundo os próprios versos do poema, "Que le crach du Panama est d'une importance plus universelle / Car il a bouleversé mon enfance" (CENDRARS, 2005, p. 105). ${ }^{6}$ E foi durante essa constatação que a mãe de Blaise Cendrars lhe falou sobre a vida dos sete irmãos dela, cujas aventuras faziam-nos aparecer com os heróis de Homero, assim como as personagens da infância de Manuel Bandeira em "Evocação de Recife". Além disso, os dois poemas são longos, respondendo a uma narratividade que o conteúdo memorialístico dos versos parece exigir, bem como o lado épico de suas personagens e, no caso do poema de Manuel Bandeira, da própria infância, repleta de aventuras e experiências.

Ainda pode-se observar outro dado em comum, de fundamental importância: os processos e as técnicas de composição são muito semelhantes nesses dois poemas. Há uma linguagem coloquial, prosaica e simples para narrar fatos do cotidiano; algumas justaposições de imagens; incorporação de falas; elementos da cultura popular e da tradição; verso livre tão marcante pela sua perfeição formal, além do equilíbrio entre as manifestações do consciente e do inconsciente na criação. Em Libertinagem, é possível encontrar facilmente tais aspectos ou alguns deles em quase todo o livro. Por fim, lembremos que na crônica "Cendrars daquele tempo", Manuel Bandeira valoriza a capacidade de Blaise Cendrars confidenciar os sentimentos íntimos, o que é mais um dado marcante na obra desses dois autores.

\footnotetext{
${ }^{5}$ A tradução desses versos é: "Livros / Há livros que falam do canal do Panamá / Não sei o que dizem os catálogos das bibliotecas / E não ouço os jornais financeiros / Embora os boletins da Bolsa sejam a nossa oração quotidiana / O canal do Panamá está intimamente ligado à minha infância..."

${ }^{6}$ Tradução de Liberto Cruz: "Que o 'Krach' do Panamá é de uma importância mais universal / Porque me perturbou a infância”.
} 
Trata-se de uma série de apropriações de técnicas cendrarsianas que, na maior parte dos casos, passou longe dos olhos da fortuna crítica sobre a poesia de Manuel Bandeira. As razões disso se relacionam com o fato de a poética de Blaise Cendrars ser comumente lida a partir de algumas obras oswaldianas, como o seu primeiro manifesto e o livro Pau-brasil. Em função disso, a única relação de influência já estabelecida do poeta franco-suíço na poesia de Manuel Bandeira só diz respeito ao "Poema tirado de uma notícia de jornal", cujas características o aproximam facilmente dos elementos mais típicos da apreciação dos modernistas acerca da poesia de Blaise Cendrars, como demonstrou muito Davi Arrigucci Jr.

\section{Referências bibliográficas:}

ANDRADE, Oswald de. Blaise Cendrars. Um mestre da sensibilidade contemporânea. In: EULÁLIO, Alexandre. A aventura brasileira de Blaise Cendrars: ensaio, cronologia, filme, depoimentos, antologia, desenhos, conferências, correspondência, traduções. 2. ed. São Paulo: Editora da Universidade de São Paulo; Fapesp, 2001.

ARRIGUCCI JR., Davi. Bandeira lê Cendrars. In: A poesia de Manuel Bandeira: humildade, paixão e morte. São Paulo: Companhia das Letras, 1990.

BANDEIRA, Manuel. Poesia e prosa. Rio de Janeiro: José Aguilar, 1958.

Andorinha, andorinha. Organização de Carlos Drummond de Andrade. Rio de Janeiro: José Olympio, 1966.

Correspondência Mário de Andrade \& Manuel Bandeira. Organização, introdução e notas de Marcos Antonio de Moraes. São Paulo: Editora da Universidade de São Paulo; Instituto de Estudos Brasileiros, 2000 (Coleção Correspondência Mário de Andrade).

\& Naify, 2008.

Crônicas inéditas - I. Organização de Júlio Castañon Guimarães. São Paulo: Cosac

CENDRARS, Blaise. Poesia em viagem. Tradução, seleção e notas de Liberto Cruz. Lisboa: Assírio \& Alvim, 2005.

EULÁLIO, Alexandre. A aventura brasileira de Blaise Cendrars: ensaio, cronologia, filme, depoimentos, antologia, desenhos, conferências, correspondência, traduções. 2. ed. São Paulo: Editora da Universidade de São Paulo; Fapesp, 2001.

\section{Manuel Bandeira desguises Blaise Cendrars}

Abstract: Analysis of the critical reception of Blaise Cendrars in Brasil. A more accurate view on the reception of the work of Blaise Cendrars by Manuel Bandeira, based on the 
$\begin{array}{llllllll}\mathbf{R} & \mathbf{E} & \mathbf{V} & \mathbf{I} & \mathbf{S} & \mathbf{T} & \mathbf{A} & \text { N. } 25-2013.1 \text { - EDUARDO COELHO }\end{array}$

studies of the letters, chronicles and poems of the "recifense" writer. Critical approaches of the "cendrarsiana" poetry, emphasizing its most remarable transformations during the 10's and 20's. A research on the aspects of Cendrars' poetry that can be traced in Oswald de Andrade and Manuel Bandeira's works. A reading on the attempt of "erasing" the presence of Blaise Cendrars in the poetic of Manuel Bandeira.

Key words: Poetry. Modernism. Manuel Bandeira. Blaise Cendrars.

Recebido em: 05 de junho de 2013.

Aprovado em: 10 de julho de 2013. 